\title{
The effects of venting and decompression on Yellow Tang (Zebrasoma flavescens) in the marine ornamental aquarium fish trade
}

Emily S Munday, Brian N Tissot, Jerry R Heidel, Tim Miller-Morgan

Each year, over 45 countries export 30 million fish from coral reefs as part of the global marine ornamental aquarium trade. This catch volume is affected by collection methods that cause mortality. Barotrauma caused by forced ascent of collected fish from depth has been determined to be a cause of post-collection mortality. The detrimental effects of barotrauma can be prevented by decompression, or mitigated with venting (puncturing the swim bladder to release expanded internal gas). To further evaluate the effects of collection methods on fish stress and mortality, we conducted the first comprehensive study on the effects of barotrauma prevention and mitigation practices on marine ornamental fish. We examined the effects of three ascent treatments, each with decompression stops of different frequency and duration coupled with or without venting, on sublethal effects and mortality in yellow tang (Zebrasoma flavescens), using histology and serum cortisol measurements. In $Z$. flavescens subjected to ascent without decompression stops or venting, a mean post-collection mortality of $6.2 \%$ occurred within $24 \mathrm{~h}$ of capture. Common collection methods in the fishery, ascent without or with one decompression stop followed by venting, resulted in no mortality. Histopathologic examination of heart, liver, head kidney, and swim bladder tissues in fish $0 \mathrm{~d}$ and $21 \mathrm{~d}$ postcollection revealed no significant lesions in any treatment group. Ascent without decompression stops resulted in significantly higher serum cortisol than ascent with many decompression stops, and venting alone did not affect cortisol. Future work should examine links in the supply chain following collection to determine if further handling and transport stressors affect survivorship and sublethal effects. 
2 Emily S. Munday ${ }^{1 *}$, Brian N. Tissot ${ }^{2}$, Jerry R. Heidel ${ }^{3}$, and Tim Miller-Morgan ${ }^{3,4}$

3 *Corresponding author: Clark Fork Watershed Education Program, The Institute for Educational

4 Opportunities, Montana Tech of the University of Montana, 1300 W Park Street, Butte, MT, 59701,

5 USA. Email: emily.munday@gmail.com, Tel: 1 + 857-919-1899 Fax: 406-496-4696

$6 \quad{ }^{1}$ School of the Environment, Washington State University Vancouver, Vancouver, WA, 98686

$7 \quad{ }^{2}$ Marine Laboratory, Humboldt State University, 570 Ewing St., Trinidad, CA 95570

$8{ }^{3}$ Veterinary Diagnostic Laboratory, College of Veterinary Medicine, Oregon State University, 700 SW

9 30th Street, Corvallis, OR, 97331, USA

$10{ }^{4}$ Aquatic Animal Health Program, Oregon Sea Grant/College of Veterinary Medicine, Oregon State

11 University - Hatfield Marine Science Center, 2030 SE Marine Science Drive, Newport, OR 97365

12

13

14

15

16

17

18

19 
21 Each year, over 45 countries remove and export 14-30 million fish from coral reefs as part of the marine ornamental aquarium trade (Bruckner 2005; Wood 2001). Although $\sim 90 \%$ of freshwater aquarium fish are successfully cultivated in aquaculture facilities, most tropical marine aquarium fish are wild-caught (Wood 2001). Collecting live fish for the aquarium trade involves removing reef fish from SCUBA diving depths $(\sim 10-35 \mathrm{~m})$ to the surface. Collection is followed by transporting fish

26 from the collection site to an export facility where they are held for 1-7 days prior to shipment. The fish are then packaged in plastic bags with enough water to turn around in and $100 \%$ oxygen, placed in boxes, and shipped to an import facility where they may be held for several days. The fish then are transported to a retail store, and finally, to a hobbyist aquarium. Mortality may occur at any point in this supply chain, impacting each participant in the industry, and negatively affecting coral reefs

31 through increased collection pressure to replace losses (Stevenson et al. 2011; Tissot et al. 2010).

32 Aquarium fisheries that use destructive fishing practices (e.g. cyanide is used to stun ornamental fish

33 for ease of capture) have high fish mortality, and this practice is still widespread (Hall and Bellwood

34 1995; Hanawa et al. 1998; Rubec et al. 2001; Rubec and Cruz 2005; Bell et al. 2009). While fishers in

35 Hawaii do not use cyanide to collect fish (Walsh, et al. 2004), and immediate mortality is low $(<1 \%)$

36 (Stevenson et al. 2011), levels of delayed mortality morality are unknown. Because fish move rapidly

37 through the supply chain, it is possible that aquarium fishers are unaware of collection methods that

38 result in mortality further along the supply chain. Economically, delayed mortality shifts the burden of

39 fish death and monetary loss from the collector to those further along the supply chain (e.g. the

40 importer, or hobbyist) while also increasing the demand for fish and exacerbating pressure on coral

41 reef ecosystems. Identifying methods that cause delayed mortality would reduce the overall mortality 
42 of aquarium fish in the aquarium trade, and thus the number of fish removed from the reef to 43 compensate for these losses.

44 In order to identify industry methods that cause delayed mortality in aquarium fish, it is necessary to

45 examine each link in the aquarium fish trade supply chain both independently and in succession. In this

46 study, we examine the first step in the supply chain: removing fish from depth (15-18 $\mathrm{m})$ to the surface.

47 Mortality caused by removing live fish from coral reef depths to the surface is an important and

48 controversial issue affecting the aquarium fishery, and to our knowledge, ours is the first study to

49 examine this problem.

50 To ensure that fish survive the transition from depth to the surface, aquarium fishers must either

51 prevent or mitigate barotrauma. Fish experience barotrauma when they are brought to the surface. As

52 water pressure decreases, the volume of swim bladder gas increases. This phenomenon is a result of

53 Boyle's Law, in which decreasing pressure causes an exponential increase in gas volume. Barotrauma

54 signs in fish manifest both externally and internally and include: positive buoyancy caused by

55 overexpansion of the swim bladder; bulging of the eyes, or exophthalmia; and protrusion of the

56 intestine from the cloaca. While barotrauma has not been studied in shallow-dwelling (15-18 $\mathrm{m})$ reef

57 fish caught for the aquarium trade, there is ample research on the effects of depth changes on deeper

58 dwelling (20-152 m) fish caught commercially and recreationally for consumption (Table 1).

59 Prior research has demonstrated that fish continue to exhibit sublethal injuries (not having caused

60 death) for extended periods. Rupture of the outer layer of the swim bladder (tunica externa) persisted

61 for at least one month after collection in rockfish (genus Sebastes) (Pribyl 2010). This indicates that

62 sublethal signs of barotrauma persist long after the initial trauma occurs. Knowing this, we predict that 
63 fish collected for the live ornamental aquarium trade also suffer sublethal injuries that could result in 64 delayed mortality.

65 Because barotrauma can be potentially fatal to both shallower-dwelling aquarium fish and deeper66 dwelling food fish alike, fishers implement methods that either prevent or mitigate it. Venting is a 67 method that mitigates barotrauma and involves puncturing a fish swim bladder with a hypodermic needle to allow gases to escape the swim bladder, relieving positive buoyancy. Decompression, in contrast, is a method that prevents barotrauma. Decompression involves transporting fish from depth to the surface over a longer period of time, which allows expanding gases to be removed from the swim bladder, resulting in a fish that is not subjected to barotrauma at all. Fishers implement one, or some combination of both of these methods in order to help fish survive the pressure transition. While the use of venting and decompression on aquarium fish has been documented (Randall 1987; Pyle 1993; LeGore et al. 2005), ours is the first study to evaluate the efficacy of each of these procedures in preventing mortality.

In deeper-dwelling fishes, decompression takes a long time - up to several days (Parker et al. 2006;

Pribyl 2010). In order to prevent barotrauma, one must allow adequate time for fish to naturally remove gas from the expanding swim bladder. Likewise, in Hawaii where fishers collect shallowdwelling reef fish, ascent with multiple decompression stops can be time-consuming ( $\sim 2$ hours). Providing fish time to naturally decompress and remove swim bladder gases prevents fishers from moving from one reef site to another because fish collection containers must be attached to the surface vessel. Fishers would rather remove fish from depth quickly in order to move to another reef site, return to depth, and collect more fish. However, bringing fish up to the surface quickly without decompression stops results in barotrauma. To mitigate this barotrauma, fishers use venting. 
85 Research on deeper-dwelling food fishes disagree that venting reduces fish mortality. This is largely an 86 artifact of the differences in species and depths the studies examine (Gotshall 1964; Keniry et al. 1996;

87 Shasteen and Sheehan 1997; Collins et al. 1999; Kerr 2001; Nguyen et al. 2009; Wilde 2009). as well

88 as differences in the length of time fish are observed in captivity. We predict that long-term holding

89 will allow us to definitively conclude how collection methods affect fish health.

90 As previously stated, fishers often use some combination of decompression and venting. For example,

91 it is common for aquarium fishers to perform one or several decompression stops, pausing in the water

92 column at intermediate depths before removal to the surface (LeGore et al. 2005; Stevenson et al.

93 2011). In Hawaii, fishers typically vent the fish following this practice. While these methods of

94 barotrauma prevention and mitigation likely positively affect fish health and mortality, these practices

95 are controversial among the animal rights community. Such groups in Hawaii have repeatedly

96 proposed legislation that would ban the harvest of marine species for the aquarium trade based on

97 animal cruelty claims (see Lauer 2011; Talbot 2012; Wintner 2010, 2011). Groups opposed to venting

98 claim that it inflicts stress and mortality on fish, while collectors maintain that venting is necessary for

99 fish survival. People who oppose venting have suggested that decompression be used instead. While

100 we may not solve the values conflicts driving in this controversy, we do hope to inform pending

101 management decisions related to aquarium fish collection in Hawaii.

102 In our study, we seek to: (1) Determine short- and long-term mortality of reef fish caught for the

103 aquarium trade subjected to the barotrauma prevention and/or mitigation practices of decompression

104 and venting, respectively; (2) Examine sublethal effects of collection that could result in delayed

105 mortality.

106 Methods 


\section{Experimental Design}

108 This study was conducted on the west coast of the island of Hawaii in June-July 2011. The Yellow

109 Tang (Z. flavescens) was selected as the study animal because it is the most commonly targeted

110 aquarium fish species in Hawaii, consistently composing nearly $80 \%$ of the total catch of aquarium fish

111 there (Cesar et al. 2002; Tissot and Hallacher 2003; Walsh et al. 2004; Williams et al. 2009). In

112 addition, Acanthuridae, the family encompassing Yellow Tang and other surgeonfishes, is one of the

113 most common families targeted globally in the live aquarium trade (Rhyne et al., 2012). Therefore,

114 understanding how collection practices affect Yellow Tang health and survival is especially relevant to

115 the marine aquarium fishery.

116 To examine the effects of collection practices on mortality of Yellow Tang, we used a fully crossed

117 factorial experimental design. Three decompression treatments (no decompression stops, one

118 decompression stop, many decompression stops) were coupled with venting (yes, no) in all possible

119 combinations ( $k=6$ treatments) (Figure 1). Each of the six treatments was replicated three times, with

$120 \mathrm{n}=20$ fish in each replicate for a total of 360 individual fish.

121 Yellow Tang were subjected to collection methods typical of the fishery, as elucidated through

122 interviews with active aquarium fishers. Fish were collected between 15-18 m depth, reflecting the

123 range frequented by Hawaiian collectors (Stevenson et al. 2011). In order to accurately reflect methods

124 used by aquarium fishers, an aquarium fisher with over 15 years of experience collected the fish. One

125 aquarium fisher performed the experiment in order to maintain consistent methods throughout the

126 experiment. Working with several fishers would be ideal, but this was not logistically or financially

127 feasible. Fish collection occurred on SCUBA using a barrier net, as described by Stevenson et al. 
128 (2011). Following capture, fish were transferred to containers assigned to an ascent treatment.

129 Following ascent to the surface vessel, half of the fish were vented and half were not.

130 Three ascent treatments were used: 1) ascent without decompression stops, 2) ascent with one

131 decompression stop, and 3) ascent with multiple decompression stops. The rate of ascent between

132 decompression stops was $0.25 \mathrm{~m} / \mathrm{s}$ for all treatments, the recommended SCUBA ascent rate and the rate

133 fishers ascend while transporting fish from depth to the surface. Fish subjected to ascent without

134 decompression were brought directly to the surface from depth. Fish subjected to ascent with one

135 decompression stop were brought up to half the maximum depth for a 45 min decompression stop, and

136 then brought to the surface. Fish subjected to multiple decompression stops were brought up $3 \mathrm{~m}$ every

$13715 \mathrm{~min}$. At $10 \mathrm{~m}$ (2 atm), these fish were brought up $1.5 \mathrm{~m}$ every $15 \mathrm{~min}$ because the volumetric

138 change resulting from the decrease in pressure is especially great the last few meters of ascent. As is

139 typical in the fishery, venting was performed by the fisher on the fishing vessel using a $20 \mathrm{G}$

140 hypodermic needle, replaced after approximately 50 fish. Each fish was held out of water for less than

$1413 \mathrm{~s}$ by the fisher while the needle was inserted through the body wall toward the swim bladder, caudal

142 to the pectoral fin and ventral of the lateral line. Following collection, fish were transported in the

143 vessel's live well until they reached the holding facility. During collection and transit from collection

144 site to port, fresh seawater was continuously circulated through the live well.

145 Initial histologic diagnostics were performed on fish ( $\mathrm{n}=5$ in each replicate group) immediately upon

146 arrival at the holding facility to determine baseline health as well as to assess the immediate effects of

147 venting and decompression. All fish that died were examined histologically to identify lesions that

148 could have contributed to death. A final histologic diagnostic examination was also performed on

149 surviving fish at the conclusion of the holding period. Serum cortisol concentration was also measured 
150 upon arrival at the aquaculture facility. Serum cortisol serves as a proxy for stress in fish (Donaldson 151 1981).

\section{Holding Period}

153 Post-collection, fish were observed for $21 \mathrm{~d}$ at an aquaculture facility located at the Natural Energy

154 Laboratory Hawaii Authority (NELHA) in Kona, Hawaii provided with natural surface seawater at 155 ambient temperatures. The experimental duration was chosen because after interviewing fishers

156 operating in Kona, Hawaii, we determined that $21 \mathrm{~d}$ represents a reasonable time period for a fish to be

157 transferred from the reef to a retailer or hobbyist in this particular chain. In addition, swim bladder

158 healing in rockfish has been observed after $21 \mathrm{~d}$ (Parker et al. 2006) and is sufficient time to allow skin

159 and muscle regeneration in fish (Roberts 2010). Therefore, fish exhibiting lesions after $21 \mathrm{~d}$ may not

160 have fully recovered in a supply chain environment and could be categorized as having sublethal

161 effects from collection.

162 Fish were held in $1 \mathrm{~m}$ diameter mesh floating cages within three 10,000 1 pools, which served as

163 replicate blocks, each containing all six treatments. Incoming seawater was filtered to $5 \mu \mathrm{m}$, and set to

164 flow through each pool at a rate of 1 volume/d. Pools were exposed to natural sunlight, and

165 temperature and salinity were measured twice daily. All fish were fed a natural algae diet (Ulva

166 fasciata) rich in nutrients absorbed from food fish outflow in the aquaculture facility for biofiltration.

167 Fish were monitored daily and mortality was recorded. Standard length (SL) (from snout to base of

168 caudal fin) of each fish was measured. Following mortality, fish were placed in $10 \%$ neutral buffered

169 formalin for histopathology; the operculum was removed and body cavity opened to facilitate proper

170 formalin fixation of the internal tissues. Moribund fish were humanely euthanized using an overdose

171 solution (> $250 \mathrm{mg} / \mathrm{l})$ of tricaine methanesulfonate (MS-222) (Sigma Aldrich). 


\section{Histopathology}

173 To determine the sublethal effects of collection methods, fish $(n=5)$ were chosen randomly from each

174 replicate treatment group immediately upon arrival to the holding facility $(0 \mathrm{~d})$ and at the end of the

175 holding period (21 d) for histopathology. Fish used for histopathology were euthanized using an 176 overdose solution of MS-222, placed on ice, and shipped within 48 h to Oregon State University's

177 (OSU) Veterinary Diagnostic Laboratory (VDL) for histologic examination. Fish that died during the 178 experiment were fixed in 10\% neutral buffer formalin as described above and examined.

179 Formalin-fixed fish were immersed for $24 \mathrm{~h}$ in Cal-Ex II (Fisher Scientific) to decalcify bone, and

180 serial cross sections were processed using standard histologic techniques, sectioned at $5 \mu \mathrm{m}$, and

181 stained with hematoxylin and eosin. Brown-Hopps Gram stain was used as necessary to assess for the

182 presence of bacteria. All slides were examined using a Nikon Eclipse 50i microscope. Histologic

183 examination focused upon gill, heart, kidney, liver, swim bladder, and intestine.

184 Primary Stress Response

185 Because of the potential for cortisol concentrations to decrease when a stressor subsides, blood samples

186 were collected from fish immediately upon arrival to the holding facility. Fish $(\mathrm{n}=2)$ were anesthetized

187 from each treatment replicate group using MS-222 prior to drawing 0.3-1.0 ml blood from the heart

188 using a $25 \mathrm{G} 2.54 \mathrm{~cm}$ needle and $3 \mathrm{ml}$ syringe. Cardiac puncture was necessary because the small size

189 of the fish. Following blood sample collection, fish were euthanized using an overdose solution of MS-

190 222. To determine Yellow Tang ocean baseline cortisol concentration, blood was collected from fish

$191(\mathrm{n}=4)$ underwater on SCUBA at capture depth within 3 min of capture. Blood was injected into $3 \mathrm{ml}$

192 vacutainer tubes with no additive (Becton-Dickinson), placed on ice, and centrifuged at 3,000 rpm for

$19310 \mathrm{~min}<1 \mathrm{~h}$ later. Serum supernatant was transferred to a clean vacutainer tube with no additive, 
194 placed on ice, and frozen $<1 \mathrm{~h}$ later for $\leq 40 \mathrm{~d}$ in a non-frostless freezer, and transported overnight on

195 dry ice to the OSU Department of Fisheries and Wildlife for analysis.

196 Serum cortisol concentrations were determined using radioimmunoassay (RIA) as described by

197 Redding et al. (1984). Total binding, the ratio of the radiolabeled cortisol bound to the antibody to the

198 total amount of radiolabeled cortisol in the sample, was 40-50\%. Samples showed adequate

199 parallelism, and 3.9-500.0 $\mathrm{ng} / \mathrm{ml}$ cortisol standards were used.

\section{Statistical Methods}

201 Statistical analyses were performed using the Minitab 15 Statistical Software program. To meet 202 assumptions of normality and homogeneity of variance, data were transformed to square root (fish SL) 203 or $\log$ (cortisol). A one-way t-test was used to compare mean cortisol concentrations of each treatment 204 group with the ocean baseline parameter. A two-way ANOVA was used to compare mean cortisol 205 concentrations, with decompression treatment and venting as fixed factors and replicate block as a 206 random factor. Tukey's multiple comparisons test was used to determine significant differences 207 between levels within each factor.

\section{Results}

\section{Mortality}

210 Sizes of Yellow Tang in this study ranged from $5.0-10.0 \mathrm{~cm}$ SL with a mean value of $7.2 \mathrm{~cm}(S E=0.05$ $211 \mathrm{~cm}$ ). Mortality occurred $<24 \mathrm{~h}$ post-collection in fish subjected to ascent without decompression stops 212 or venting, with a mean mortality of $6.2 \%(S E=0.6 \%)$. No mortality occurred in the other experimental 213 treatments. 
214 The incidence of mortality was consistent with observations of the frequency and severity of external

215 barotrauma signs. These included high frequency of positive buoyancy, bloating, prolapse of the

216 intestine from the cloaca, and exophthalmia (Figure 2) in fish subjected to ascent without

217 decompression stops. Venting relieved positive buoyancy and vented fish became neutrally or

218 negatively buoyant (Figure 2).

\section{Histopathology}

220 Histopathology of gill, heart, kidney, liver, swim bladder, and intestine failed to detect significant 221 inflammation, necrosis, or gas embolism associated with barotrauma or venting in any treatment, in 222 both the short- and long-term. A venting wound was detected in a fish subjected to ascent with many 223 decompression stops and venting at day 0 . However, this lesion consisted only of locally extensive 224 necrosis of body wall musculature and a localized influx of neutrophils surrounding the needle track 225 and not significant widespread infection (Figure 3).

\section{Primary Stress Response}

227 The mean ocean baseline cortisol concentration was $8.9 \mathrm{ng} / \mathrm{ml}(S E=4.96 \mathrm{ng} / \mathrm{ml})$ and in some cases was 228 at or below the detection limit for the assay $(3.9 \mathrm{ng} / \mathrm{ml})$. All treatment groups were significantly 229 elevated above the baseline cortisol concentration (One-way t-test; $p<0.05$ ). There was no significant 230 interaction between decompression treatment and venting. Decompression treatment significantly 231 affected cortisol concentration (Two-way ANOVA: $F=4.26 ; d f=2,12 ; p=0.03$ ) (Figure 4). Ascent 232 without decompression stops resulted in a significantly higher mean cortisol concentration $(M=58.8$ $233 \mathrm{ng} / \mathrm{ml}, S E=8.7 \mathrm{ng} / \mathrm{ml})$ than ascent with many $15 \mathrm{~min}$ decompression stops $(M=35.5 \mathrm{ng} / \mathrm{ml}, S E=5.3$

$234 \mathrm{ng} / \mathrm{ml}$ ), with neither treatment being significantly different from ascent with one 45 min decompression 235 stop $(M=35.2 \mathrm{ng} / \mathrm{ml}, S E=4.3 \mathrm{ng} / \mathrm{ml})$. Ascent without decompression stops produced the highest 
236 observed cortisol concentration $(101.49 \mathrm{ng} / \mathrm{ml})$, whereas the highest observed cortisol concentrations in 237 fish subjected to one and many decompression stops were 59.09 and $68.03 \mathrm{ng} / \mathrm{ml}$, respectively. While 238 venting resulted in higher mean cortisol concentration $(M=47.7 \mathrm{ng} / \mathrm{ml}, S E=6.9 \mathrm{ng} / \mathrm{ml})$ than the no 239 venting treatment $(M=38.2 \mathrm{ng} / \mathrm{ml}, S E=4.3 \mathrm{ng} / \mathrm{ml})$, this difference was not statistically significant.

\section{Discussion}

241 With the objective of informing management on collection practices in the aquarium trade, our study 242 focused on the short- and long-term mortality of reef fish subjected to decompression and venting as 243 barotrauma prevention and mitigation practices, respectively. Overall, we found that venting prevented

244 immediate mortality in fish subjected to ascent without decompression stops. Ascent significantly 245 elevated serum cortisol above baseline concentrations, and ascent without decompression stops 246 resulted in significantly higher serum cortisol concentrations than ascent with many stops. Venting, 247 however, did not significantly affect cortisol concentration. In the following sections, we explain our 248 results, suggest future research recommendations, and discuss implications for management of this 249 fishery.

\section{Mortality}

251 We found that the methods commonly used in this fishery (ascent without decompression stops, or 252 ascent with one decompression stop, followed by venting) resulted in no immediate or delayed 253 mortality. Ascent without decompression stops followed by venting resulted in no mortality, while fish 254 subjected to ascent without decompression stops and no venting was the only treatment group in which 255 mortality occurred. Venting alleviated positive buoyancy in fish following ascent with no 256 decompression stops and in this way mitigated barotrauma sufficiently to prevent short-term mortality. 257 Neutral buoyancy allowed fish to control body position and avoid colliding with the transport container 
258 during transport from reef to harbor. This is in contrast to fish subjected to ascent without

259 decompression or venting, which exhibited positive buoyancy and were at risk of acquiring secondary 260 transport-related injuries.

261 Additional factors that may influence post-collection mortality, but are outside the scope of this study, 262 include collection depth, body size, and species. We examined fish collected from 15-18 m depths, 263 which is typical for the Hawaii Yellow Tang fishery, though fishers do exceed this range (i.e. $\geq 27 \mathrm{~m}$ ) 264 when targeting other species (Stevenson et al. 2011). At deeper depths, the effects of decompression 265 and venting may differ, and it is known that fish mortality and occurrence of barotrauma increases with 266 capture depth (Collins et al. 1999; St John and Seyers 2005; Hannah et al. 2008; Jarvis and Lowe, 267 2008; Campbell et al. 2010). Interviews with fishers indicate that fish collected from $>25 \mathrm{~m}$ require 268 more decompression time and venting while at depth, or several venting applications during ascent. 269 Fishers have also mentioned that larger fish exhibit more severe external barotrauma symptoms than 270 smaller fish of the same species, which is similar to findings in studies on deeper-dwelling food fishes 271 (Hannah et al. 2008; St John and Seyers 2005). Just as different deeper-dwelling food fish species 272 exhibit different responses to ascent rate (Hannah and Matteson 2007; Jarvis and Lowe 2008; Pribyl 273 2010), aquarium fish species reportedly react differently to ascent rate and venting. These differences 274 are likely caused by variation in body shape, tissue durability, and swim bladder volume between 275 species. Methods used by fishers reflect these species differences, with practices such as performing 276 venting on more delicate, soft-bodied fish like angelfish (Pomacanthidae) underwater to prevent swim 277 bladder expansion. Examining differences among aquarium fish species of varying sizes and 278 investigating the variety of techniques employed by fishers during collection would provide further 279 insight into the prevalence and effectiveness of aquarium fish barotrauma prevention and mitigation 280 methods. 
281 Histopathology

282 Histopathology did not detect significant widespread inflammation, organ damage or infection caused 283 by venting. Only one case of a needle wound was found that consisted of localized necrosis and 284 inflammation, with no visible evidence of infection. It is possible that histologic sectioning of tissues 285 missed similar lesions in other fish, but this was minimized by focusing the sampling at the site 286 consistently used by fishers for venting. However, the objective of histopathology in our study was to 287 determine if widespread inflammation or tissue damage was present in fish indicating significant 288 injury, which was not found. If such injuries were present, they would have been detected in multiple 289 sections of the tissues surrounding the venting wound.

290 Wound healing with no evidence of ongoing necrosis or inflammation, as seen in these fish, indicates 291 that the venting procedure does not pose a significant threat to fish survival post-collection, nor does it 292 cause significant sublethal effects. However, we caution that the fish in our study were held in an 293 aquaculture facility for $21 \mathrm{~d}$ without the additional handling and transport stressors they would 294 normally experience in the supply chain, thus potentially promoting recovery from injuries inflicted 295 during collection. It is possible that additional stressors of the supply chain diminish the efficacy of 296 venting in promoting long-term fish survival.

297 Because aquarium fish exhibited external signs of barotrauma similar to those observed in deeper298 dwelling food fishes, we expected internal barotrauma signs to be similar as well. However, we did not 299 detect lesions resulting from barotrauma, even in fish subjected to ascent without decompression.

300 Externally visible signs of barotrauma did occur, however. Positively buoyant fish were bloated and 301 had intestinal prolapse at the cloaca. Although not examined in this study, it is likely that organ 302 displacement by the swim bladder occurred in these fish, an internal barotrauma sign observed in 
303 deeper-dwelling food fishes (Rogers et al. 2008). Determining if organ displacement occurs, and if

304 venting relieves this issue in aquarium fish would further our understanding of the mechanisms with

305 which venting reduces mortality in fish subjected to ascent without decompression.

\section{Primary Stress Response}

307 Our results indicate that all collection methods produced elevated cortisol concentrations above the 308 ocean baseline level. Though we did not perform stress treatments on Yellow Tang to determine a 309 cortisol level that corresponds to a stressed state, Soares et al. (2011) did so with a closely related 310 acanthurid (Ctenochaetus striatus). While cortisol concentrations vary between species (Barton and 311 Iwama 1991), stressed (45-65 ng/ml) and non-stressed (10-25 ng/ml) cortisol concentrations in $C$. 312 striatus suggest that venting increased stress in fish subjected to ascent without decompression though 313 this was not statistically significant. Despite this increase, we emphasize that venting did mitigate 314 positive buoyancy and ultimately prevented mortality. It appears that venting alone is a short-term 315 stressor, but prevents mortality in fish subjected to ascent without decompression stops.

316 Future studies should investigate if cortisol levels subside, or remain elevated in the rest of the supply

317 chain. Handling in and transport between export, import, and retail facilities may exacerbate collection318 induced stress. Because chronic stress results in immune system suppression (Barton and Iwama 1991;

319 Barton 2002), fish experiencing chronic stress are more susceptible to infection, disease, and delayed 320 mortality. Because hobbyists whose aquarium fish die often replace these fish, delayed mortality is a 321 great driver of aquarium fish demand (Tissot et al. 2010). It is likely that stress plays a role in this 322 mortality, and future studies should examine stress as it relates to handling in and transport between 323 each link in the supply chain beyond collection.

\section{Implications for Management}


325 While our work adds to scientific knowledge regarding collection practices of aquarium fish in Hawaii, 326 it is also relevant to the global trade. Yellow Tang and other surgeonfish (family Acanthuridae), are 327 one of the most common families targeted globally in the live aquarium trade (Rhyne et al., 2012). Our 328 results also improve our understanding of the effects of venting. Previous studies show conflicting 329 results regarding the effects of venting on fish mortality (Gotshall 1964; Keniry et al. 1996; Nguyen et 330 al. 2009; Wilde 2009). Our results indicate that when performed properly, venting does not cause 331 mortality or inflict significant sublethal injuries, though we caution that our inference is limited to a 332 single species.

333 Though animal rights groups in Hawaii criticize venting, we did not find that it caused mortality or 334 sublethal injuries in Yellow Tang. Banning venting may increase mortality rates if fishers implemented 335 ascent without decompression. While opponents of venting have suggested that slow decompression be 336 used instead, the time required to naturally decompress fish could be economically prohibitive. It is 337 also worth pointing out the dichotomy of venting in the recreational fisheries versus the aquarium 338 trade. Recreational fishers are often encouraged to vent fish before returning them to the water (see 339 Kerr, et al. 2001; Stevely et al. 2011; Theberge and Parker 2005), while venting remains controversial 340 in the aquarium trade.

341 In conclusion, we determined that the methods commonly used by aquarium fishers in Hawaii do not

342 cause mortality in Yellow Tang. However, all collection methods produced elevated cortisol

343 concentrations in fish, and this warrants more investigation. Further handling in and transport between

344 links in the supply chain could cause chronically elevated cortisol concentrations in fish, exacerbating 345 stress and minor injuries inflicted during collection.

\section{Acknowledgements}


347 We thank fishers in Kona, Hawaii, especially Tyron Terrazzono, Paul Masterjohn, and Scott Brien for

348 their time, cooperation, and support. Thanks to Todd Stevenson for project guidance; Syd Kraul for use

349 of his aquaculture facility; Meghan Dailer for her hospitality and encouragement; Tony Spitzack, Cori

350 Kane, Molly Bøgeberg, and Evan Morris for project assistance; Dr. Jim Beets and Caitlin Kryss of The

351 University of Hawaii at Hilo's Marine Science Department, Dr. Bill Walsh, Laura Livnat, and Kara

352 Osada of the Hawaii Department of Aquatic Resources for logistical support and project guidance; Dr.

353 Bob Jordan and the Kona Veterinary Service for supplies; Ian McComas for centrifuge use, guidance,

354 and his time; Dr. Carl Schreck and Julia Unrein at the OSU Department of Wildlife and Fisheries

355 Laboratory for cortisol analysis and guidance with sampling protocol; Dr. Cheryl Schultz and many

356 others for manuscript edits and suggestions. This work was performed under Washington State

357 University Institutional Animal Care and Use Committee protocol \#04151-004. 
358

359

360

361

\section{References}

Barton BA. 2002. Stress in fishes: A diversity of responses with particular reference to changes in circulating corticosteroids. Integrative and Comparative Biology 42:517-525.

Barton BA, Iwama GK. 1991. Physiological changes in fish from stress in aquaculture with emphasis on the response and effects of corticosteroids. Annual Review of Fish Diseases 1:3-26.

Bell JD, Clua E, Hair CA, Galzin R, Doherty PJ. 2009. The capture and culture of post-larval fish and invertebrates for the marine ornamental trade. Reviews in Fisheries Science. 17(2): 223-240.

Brown I, Sumpton W, McLennan M, Mayer D, Campbell M, Kirkwood J, Butcher A, Halliday I, Mapleston A, Welch D, Begg GA, and Sawynok B. 2010. Journal of Experimental Marine Biology and Ecology. 385:1-7.

Bruckner AW. 2005. The importance of the marine ornamental reef fish trade in the wider Caribbean. Revista de Biologia Tropica 53:127-38.

Bruesewitz RE, Coble DW, Copes F. 1993. Effects of deflating the expanded swim bladder on survival of burbot. North American Journal of Fisheries Management 13:346-348.

Campbell MD, Patino R, Tolan J, Strauss R, Diamond SL. 2010. Sublethal effects of catch-and-release fishing: measuring capture stress, fish impairment, and predation risk using a condition index. ICES Journal of Marine Science 67:513-521.

Cesar H, van Beukering P, Pintz S, Dierking J. 2002. Economic Valuation of the Coral Reefs of Hawaii. Pacific Science 58(2):231-242.

Collins MR, McGover JC, Sedberry GR, Meister HS, Pardieck R. 1999. Swim bladder deflation in black sea bass and vermillion snapper: potential for increasing postrelease survival. North American Journal of Fisheries Management 19:828-832.

Donaldson EM. 1981. The pituitary-interrenal axis as an indicator of stress in fish. In: Pickering AD ed. Stress in Fish. New York: Academic Press Inc., 11-47.

Gotshall DW. 1964. Increasing tagged rockfish (Genus Sebastodes) survival by deflating the swim bladder. California Fish and Game 50:253-260. 
384 385 386

Hall KC, Bellwood DR. 1995. Histological effects of cyanide, stress and starvation on the intestinal mucosa of Pomacentrus coelestis, a marine aquarium fish species. Journal of Fish Biology 47:438-454.

Hanawa M, Harris L, Graham M, Farrell AP, Bendell-Young LI. 1998. Effects of cyanide exposure on Dascyllus aruanus, a tropical marine fish species: lethality, anesthesia and physiological effects. Aquarium Sciences and Conservation 2:21-34.

Hannah RW, Matteson KM. 2007. Behavior of nine Pacific rockfish after hook-and-line capture, recompression, and release. Transactions of the American Fisheries Society 136:24-33.

Hannah RW, Parker SJ, Matteson KM. 2008. Escaping the surface: the effect of capture depth on submergence success of surface-released pacific rockfish. North American Journal of Fisheries Management 28:694-700.

Jarvis ET, Lowe CG. 2008. The effects of barotrauma on the catch-and-release survival of southern California nearshore and shelf rockfish (Scorpaenidae, Sebastes spp.). Canadian Journal of Fisheries and Aquatic Sciences 65:1286-1296.

Keniry MJ, Brofka WA, Horns WH, Mardsen JE. 1996. Effects of decompression and puncturing the gas bladder on survival of tagged yellow perch. North American Journal of Fisheries Management 16:201-206.

Kerr SJ. 2001. A review of "fizzing"- a technique for swim bladder deflation. Fish and Wildlife Branch, Ontario Ministry of Natural Resources, Peterborough, Ontario. Available at http://www.rockymountainanglers.com/images/Studies\%20Reports\%20PDFs/ReviewOfFizzing Techniques.pdf. (accessed 5 September 2014).

Lauer NC. 2011, October 5. Supporters drown out opponents in testimony. West Hawaii Today. Available at http://kona.westhawaiitoday.com/sections/news/local-news/fish-collecting-banreso-passes-council.html. (accessed 5 September 2014).

LeGore RS, Hardin MP, and Ter-Ghazaryan D. 2005. Organization and operation of the marine ornamental fish and invertebrate export fishery in Puerto Rico. Revista de Biologia Tropica 53:145-153. 
411 Nichol DG and Chilton EA. 2006. Recuperation and behaviour of Pacific cod after barotrauma. ICES Journal of Marine Science. 63:83-94.

413 Nguyen V, Gravel M, Mapleston M, Hanson KC, and Cooke SJ. 2009. The post-release behavior and 414 fate of tournament-caught smallmouth bass after 'fizzing' to alleviate distended swim bladders. $415 \quad$ Fisheries Research 96:313-318.

416 Parker SJ, McElderry HI, Rankin PS, and Hannah RW. 2006. Buoyancy regulation in two species of nearshore rockfish. Transactions of the American Fisheries Society 135:1213-1223.

Pribyl AL, Schreck CB, Kent ML, and Parker SJ. 2009. The differential response to decompression in three species of nearshore Pacific rockfish. North American Journal of Fisheries Management. 29:1479-1486.

Pribyl AL. 2010. A Macroscopic to Microscopic Study of the Effects of Barotrauma and the Potential for Long-term Survival in Pacific Rockfish. D. Phil. Thesis, Oregon State University.

Pribyl AL, Kent ML, Parker SJ, and Schreck CB. 2011. The response to forced decompression in six species of Pacific rockfish. Transactions of the American Fisheries Society. 140:374-383.

Pyle R. 1993. Marine aquarium fish. Pacific Islands Forum Fisheries Agency, Honiara, Solomon Islands. Available at http://www.spc.int/DigitalLibrary/Doc/FAME/FFA/Reports/FFA_1992_055.pdf. (accesed 5 September 2014).

Randall JE. 1987. Collecting reef fish for aquaria. In Salvat B, ed. Human Impacts on Coral Reefs: Facts and Recommendations. French Polynesia: Antenne Museum E.P.H.E., 29-39.

Redding JM, Schreck CB, Birks E, Ewing RD. 1984. Cortisol and its effects on plasma thyroid hormone and electrolyte concentrations in fresh water and during seawater acclimation in yearling coho salmon, Oncorhynchus kisutch. General and Comparative Endocrinology 56:146-155.

Rhyne AL, Tlusty MF, Schofield PJ, Kaufman L, Morris JA, Bruckner AW. 2012. Revealing the appetite and volume of the marine aquarium fish trade: the volume and biodiversity of fish imported into the United States. PLoS One 7(5):e35808. doi 10.1371/journal.pone.0035808. 
438 Roberts HE. 2010. Surgery and wound management in fish. In: Roberts HE, ed. Fundamentals of Ornamental Fish Health. Ames, Iowa: Wiley-Blackwell, 185-196.

440

441

Rogers BL, Lowe CG, Fernandez-Juricich E, Frank LR. 2008. Utilizing magnetic resonance imaging (MRI) to assess the effects of angling-induced barotrauma on rockfish (Sebastes). Canadian Journal of Fisheries and Aquatic Sciences 65:1245-1249.

Rubec PJ, Cruz FP. 2005. Monitoring the chain of custody to reduce delayed mortality of net-caught fish in the aquarium trade. SPC Live Reef Fish Information Bulletin 13:13-23.

Rubec PJ, Cruz FJ, Pratt V, Oellers R, McCullough B, Lallo F. 2001. Cyanide-free net caught fish for the marine aquarium trade. Aquarium Sciences and Conservation 3:37-51.

Shasteen SP and Sheehan RJ. 1997. Laboratory evaluation of artificial swim bladder deflation in largemouth bas: potential benefits for catch-and-release fisheries. North American Journal of Fisheries Management. 17:32-37.

Soares MC, Oliveira RF, Ros AFH, Grutter AS, Bshary R. 2011. Tactile stimulation lowers stress in fish. Nature Communications 2: 534. doi: 10.1038/ncomms1547.

Stevely, J, Sweat D, Adams C, Novak R. 2011. Venting: A Guide to Releasing Reef Fish with Ruptured Swimbladders. Publication \# SGEF-162. Florida Sea Grant College Program. University of Florida, Gainesville, FL .

Stevenson TC, Tissot BN, Dierking J. 2011. Fisher behavior influences catch productivity and selectivity in West Hawaii's aquarium fishery. ICES Journal of Marine Science 68(5):813-822.

St John J, Seyers CJ. 2005. Mortality of the demersal dhufish, Glaucosoma hebraicum (Richardson 1845) following catch and release: The influence of capture depth, venting and hook type. Fisheries Research 76:106-116.

Talbot R. 2012, January 19. Senate Bills Call for Total Ban on Hawaiian Fishery: Open Season on Marinelife Collectors. Coral: The Reef and Marine Aquarium Magazine Newsletter. Available at http://www.coralmagazine-us.com/content/senate-bills-call-complete-ban-sale-hawaiianaquatic-life. (accessed 5 September 2014). 
464 Theberge S and Parker S. 2005. Release methods for rockfish. Oregon Sea Grant, Oregon State University, Corvallis, OR.

466 467

468 469 470 471

472 473 474 475 476 477 478 479 480 481 482 483 484 485 486 487 488

Tissot BN, Hallacher LE. 2003. Effects of aquarium collectors on coral reef fishes in Kona, Hawaii. Conservation Biology 17:1759-1768.

Tissot BN, Best BA, Borneman EH, Bruckner AW, Cooper CH, D’Agnes H, Fitzgerald TP, Leland A, Lieberman S, Amos AM, Sumaila R, Telecky TM, McGilvray F, Plankis BJ, Rhyne AL, Roberts GG, Starkhouse B, Stevenson TC. 2010. How U.S. Ocean Policy and Market Power Can Reform the Coral Reef Wildlife Trade. Marine Policy 34:1385-1388.

Walsh WJ, Cotton SP, Dierking J, Williams ID. 2004. Status of Hawaii's Coastal Fisheries in the New Millennium (The commercial marine aquarium fishery in Hawai‘i 1976-2003). In: Friedlander AM, ed. Hawaii Chapter, Honolulu: American Fisheries Society, 132-159.

Williams ID, Walsh WJ, Claisse JT, Tissot BN, Stamoulis KA. 2009. Impacts of a Hawaiian marine protected area network on the abundance and fishery sustainability of the Yellow Tang (Zebrasoma flavescens). Biological Conservation 142:1066-1073.

Wilde GR. 2009. Does venting promote survival of released fish? Fisheries 34(1):20-34.

Wintner R. 2010, August 12. "Maui County Council Ordinance Curbs Reef Extraction for Aquarium Trade." The Huffington Post. Available at http://www.huffingtonpost.com/robert-wintner/mauicounty-counci-ordina_b_674889.html. (accessed 5 September 2014).

Wintner R. 2011, January 27. "The Second Foot Falls on the Aquarium Trade in Maui County." The Huffington Post. Available at http://www.huffingtonpost.com/robert-wintner/a-splash-heardround-the-_b_812604.html. (accessed 5 September 2014).

Wood E, 2001. Collection of Coral Reef Fish for Aquaria: Global Trade, Conservation Issues, and Management Strategies. Marine Conservation Society, UK, 80pp. Available at http://www.eldis.org/go/home\&id=11010\&type=Document\#.VAqh_Kgqils. (accessed 5 September 2014). 


\section{Table $\mathbf{1}$ (on next page)}

External and internal signs of barotrauma observed in food fishes. 
Table 1: External and internal signs of barotrauma observed in food fishes.

\section{External}

Internal

Gotshall $1964 \quad$ Esophageal eversion

Bruesewitz et al. $1993 \quad$ Esophageal eversion

Keniry et al. $1996 \quad$ Esophageal eversion, positive

buoyancy

St John and Syers 2005 Esophageal eversion, exophthalmia

Parker et al. $2006 \quad$ Esophageal eversion

Hannah and Matteson 2007 Esophageal eversion

Hannah et al. $2008 \quad$ Esophageal eversion, exophthalmia

\begin{tabular}{|c|c|c|}
\hline Jarvis and Lowe 2008 & $\begin{array}{l}\text { Subcutaneous gas bubbles, } \\
\text { esophageal eversion, exophthalmia }\end{array}$ & $\begin{array}{l}\text { Arterial embolism, hemorrhage, } \\
\text { organ torsion }\end{array}$ \\
\hline Nichol and Chilton 2006 & Ruptured swimbladder & \\
\hline Rogers et al. 2008 & Exophthalmia & $\begin{array}{l}\text { Damage to and displacement of } \\
\text { organs surrounding swimbladder }\end{array}$ \\
\hline Pribyl et al. 2009 & Esophageal eversion, exophthalmia & Emphysema of heart ventricle \\
\hline Wilde 2009 & Esophageal eversion & \\
\hline Brown et al. 2010 & $\begin{array}{l}\text { Cloacal prolapse, exophthalmia, } \\
\text { esophageal eversion }\end{array}$ & \\
\hline Rogers 2010 & Exophthalmia & \\
\hline Pribyl et al. 2011 & Esophageal eversion & $\begin{array}{l}\text { Emphysema of heart ventricle and } \\
\text { epithelial surfaces, gas emboli in } \\
\text { rete mirabile and head kidney }\end{array}$ \\
\hline
\end{tabular}




\section{1}

Experimental design of ascent and venting treatments.

(A) Illustrates decompression stops for each ascent treatment. The rate of ascent between stops was $0.25 \mathrm{~m} / \mathrm{s}$ for all treatments. Fish subjected to ascent without decompression stops were brought directly to the surface. Fish subjected to ascent with one decompression stop were brought to half the maximum depth for a 45 min decompression stop, then brought to the surface. Fish subjected to multiple decompression stops were brought up $3 \mathrm{~m}$ every 15 min. At $10 \mathrm{~m}$ (2 atm), these fish were brought up $1.5 \mathrm{~m}$ every $15 \mathrm{~min}$. (B) Venting treatment scheme and fish sampling design. This experiment was replicated 3 times for a total sample size of $n=360$ fish. 
A Decompression Stops During Ascent to Surface

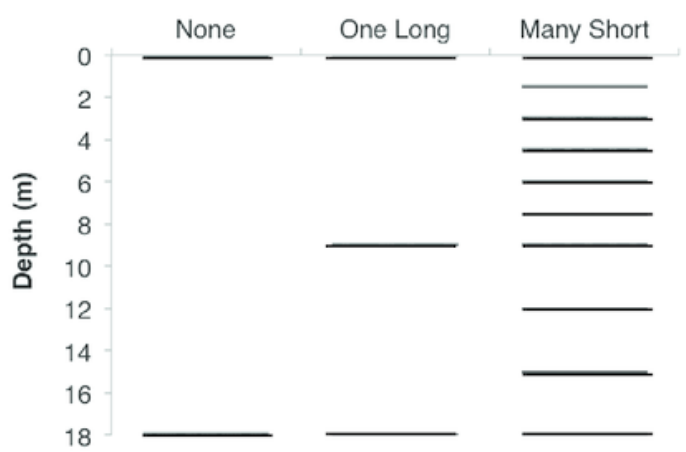

B

No decompression stops

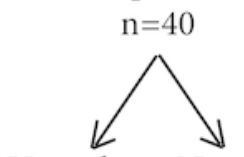

Vented

Not vented

$\mathrm{n}=20 \quad \mathrm{n}=20$

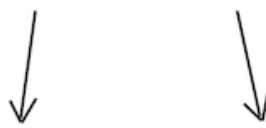

Day 1

Cortisol

$\mathrm{n}=2$

Day 1

Cortisol

$\mathrm{n}=2$

Histopathology Histopathology $\mathrm{n}=5$ $\mathrm{n}=5$

Day 21

Day 21

Cortisol sample Cortisol sample $\mathrm{n}=2$ $\mathrm{n}=2$

Histopathology Histopathology $\mathrm{n}=5$ $n=5$
One long decompression stop

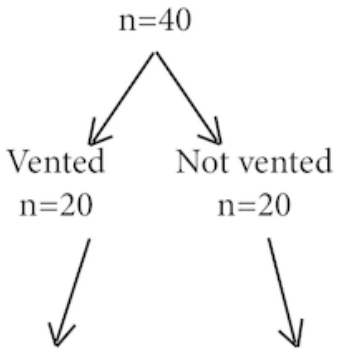

Day 1

Cortisol

$\mathrm{n}=2$

Day 1

Cortisol

$\mathrm{n}=2$

Histopathology Histopathology $\mathrm{n}=5$

$\mathrm{n}=5$

Day 21

Day 21

Cortisol sample Cortisol sample $\mathrm{n}=2 \quad \mathrm{n}=2$

Histopathology Histopathology $\mathrm{n}=5$

$\mathrm{n}=5$
Many short decompression stops

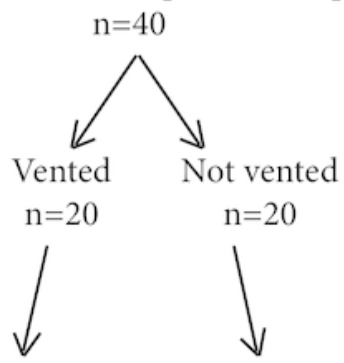

$$
\underline{\text { Day } 1}
$$

Day 1

$\mathrm{n}=2$

Cortisol

$\mathrm{n}=2$

Histopathology Histopathology

$$
\mathrm{n}=5 \quad \mathrm{n}=5
$$

Day 21

Day 21

Cortisol sample Cortisol sample $\mathrm{n}=2$ $\mathrm{n}=2$

Histopathology Histopathology $\mathrm{n}=5 \quad \mathrm{n}=5$ 
2

Barotrauma signs observed in Yellow Tang following collection.

(A) Positive buoyancy before venting and neutral to negative buoyancy following venting (B) intestinal protrusion from the cloaca and (C) exophthalmia. 


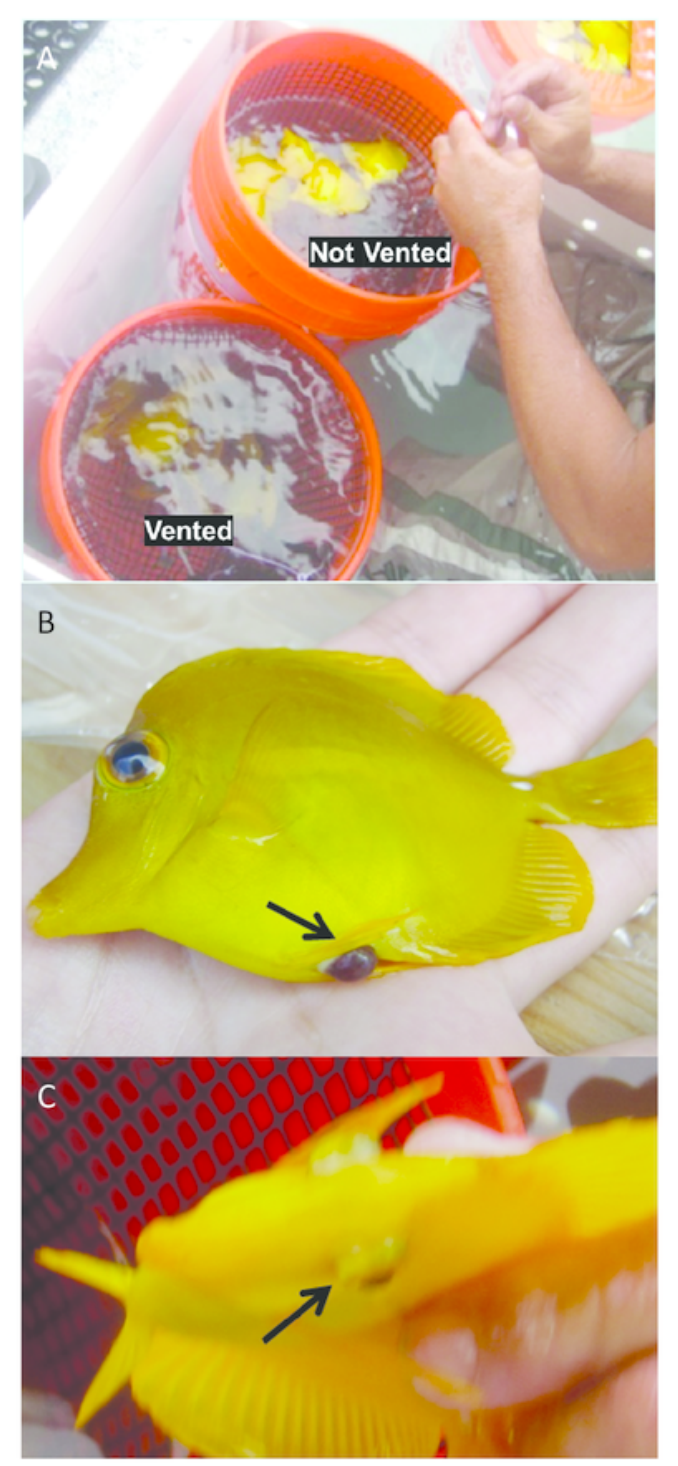




\section{3}

Histologic views of swim bladder tissues in vented Yellow Tang.

(A-B) Representative histologic views of normal Yellow Tang swim bladder tissues in vented fish at (A) 0 days and (B) 21 days. Note lack of any inflammation, edema, or necrosis in lateral body wall (bw), coelomic cavity (c) swim bladder (sb), and rete mirable (rm). (C) Histologic section of needle track in a Yellow Tang subjected to venting showing muscle cell necrosis, edema, and neutrophilic inflammation: (1) Needle track, (2) needle entry through coelomic cavity, (3) neutrophilic inflammatory response. 

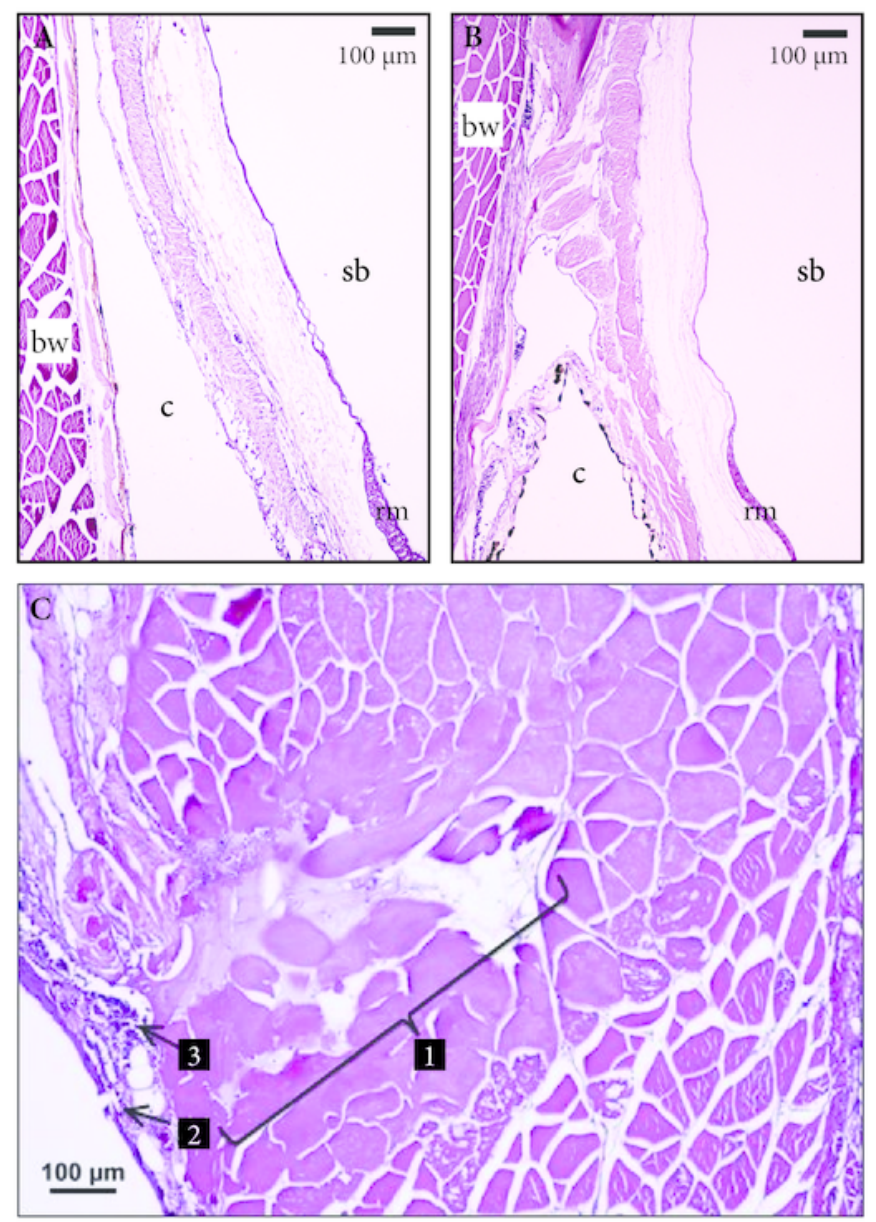
4

Cortisol concentration (mean $+/$-SE) by each treatment.

(A) venting and ascent treatments; (B) ascent treatments; and (C) venting treatments. Letter groups represent Tukey's multiple range test results comparing means. All treatment groups were significantly elevated above the ocean baseline concentration of $8.9 \mathrm{ng} / \mathrm{ml}$.

A

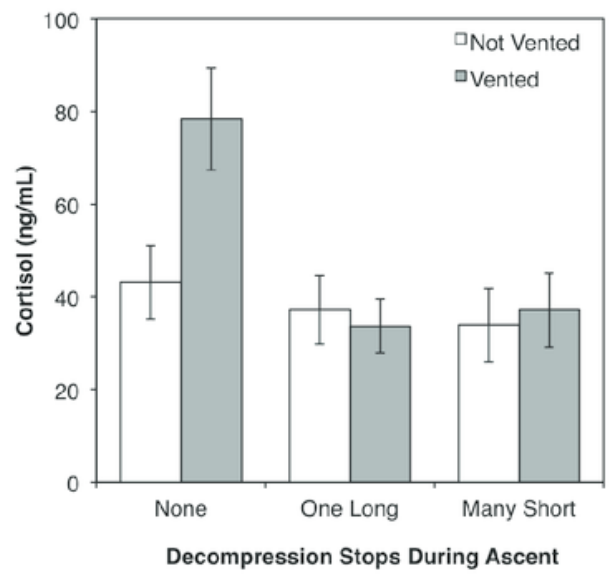

B

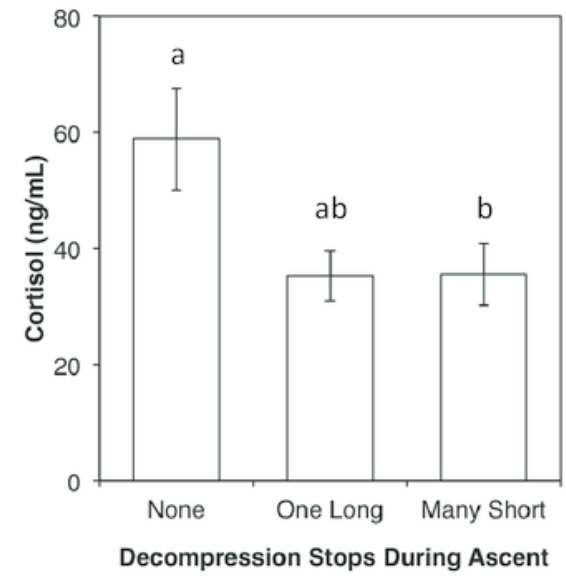

C

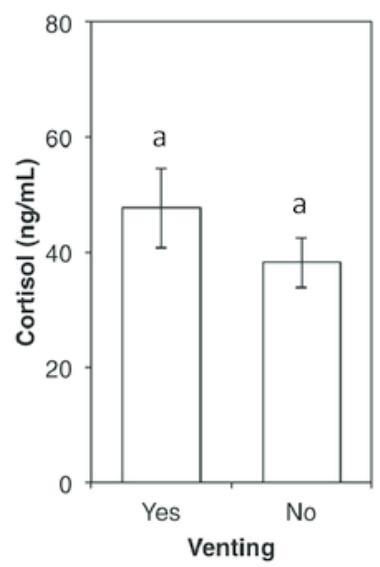

